\title{
BREVE ALUSÃO AO ATUAL ESTADO (INCONSTITUCIONAL) DE EXCEÇÃO EM QUE ESTAMOS VIVENDO E MORRENDO
}

\section{BRIEF ALLUSION TO THE CURRENT (UNCONSTITUTIONAL) STATE OF EXCEPTION IN WHICH WE ARE LIVING AND DYING}

PAOLA CANTARINI GUERRA Advogada, Professora da Universidade de Guarulhos, com pós-graduação em direito constitucional, direitos humanos e direito internacional, Mestre e Doutora em Direito pelo Programa de Estudos Pós-Graduados em Direito da Pontifícia Universidade Católica de São Paulo (PUCSP); Doutora em Filosofia do Direito pela Universidade del Salento, Itália; Pós-Doutorada em Filosofia, Arte e Pensamento Crítico pela European Graduate School, Saas-Fee, Suíça. Pós-Doutoranda em Centro de Estudos Sociais da Universidade de Coimbra, Portugal. Visiting researcher Universidade de Lisboa-Pt., Visiting researcher SNS-PISA.

WILLIS SANTIAGO GUERRA FILHO Advogado, Professor Titular do Centro de Ciências Jurídicas e Políticas da Universidade Federal do Estado do Rio de Janeiro (UNIRIO); Professor Permanente no Programa de Estudos Pós-Graduados em Direito da Pontifícia Universidade Católica de São Paulo (PUCSP). Doutor em Ciência do Direito pela Universidade de Bielefeld, Alemanha; Livre-Docente em Filosofia do Direito pela Universidade Federal do Ceará (UFC); Doutor e Pós-Doutor em Filosofia pela Universidade Federal do Rio de Janeiro (UFRJ); Doutor em Comunicação e Semiótica (PUCSP); Doutor em Psicologia Política (PUCSP). (willisguerra@hotmail.com). 


\section{RESUMO}

Objetivo: A meta desta pesquisa é a abordagem, de forma crítica, da temática do estado de exceção estudada por diversos juristas e filósofos, bem como considerações acerca dos conceitos de necropolítica e necropoder (Mbembe), em cotejo sobretudo com o pensamento de Nietzsche. Visa-se, pois, pensar a questão da biopolítica como imunologia e a transformação desta em tanatopolítica.

Metodologia: A metodologia utilizada no presente estudo é a pesquisa bibliográfica e doutrinária em obras, artigos científicos, estudos e pesquisas sobre a temática, com foco em Filosofia e do Direito.

Resultados: O sistema jurídico, em âmbito global, reagirá crescentemente contra a diversidade e, com isso, irá comprometer os fundamentos da ambiência natural e cultural humana. Este resultado é o pior a que o recrudescimento da presente crise pode levar.

Contribuições: A maior contribuição deste estudo é a superação das doenças autoimunes que a todos acometem enquanto corpo social mundial - nos termos de Roberto Esposito - destacando-se que a atual "crise alérgica" da União Europeia é um exemplo claro e menos grave do que o da Alemanha nazista analisada por esse autor, em que a enfermidade decorre da tentativa de isolamento dos contatos que põem a política a serviço da vida e não a vida a serviço de uma política mortífera, ou seja, da biopolítica transformada em tanatopolítica.

PALAVRAS-CHAVE: Violência; bode expiatório; homo sacer; estado de exceção.

\section{ABSTRACT}

Objective: To critically approach the thematic of state of exception studied by several jurists and philosophers, as well as comments about the concepts of necropolitics and necropower (Mbembe), in comparison with Nietzsche's thought. The aim is to think about the issue of biopolitics as immunology and its transformation into tanatopolitics.

Methodology: The methodology used in this study is bibliographic and doctrinal research in works, scientific articles, studies and research on the subject, focusing on Philosophy and Law.

Results: The global legal system will increasingly respond against diversity and thereby undermine the background of the natural and cultural human environment. This result is the worst that the resurgence of the present crisis can lead to.

Contributions: The major contribution of this study is the overcoming of the autoimmune diseases that affect everyone as a world social body - according to 
Roberto Esposito - highlighting that the current "allergic crisis" of the European Union is a clear and less serious example than that of Nazi Germany analyzed by the author, in which the disease stems from the attempt to isolate the contacts that directs politics at the service of life and not life at the service of a deadly policy, that is, of biopolitics transformed into tanatopolitics.

KEYWORDS: Violence; scapegoat; homo sacer; state of exception.

\section{INTRODUÇÃO: DA BIOPOLÍTICA À TANATOPOLÍTICA, E DA NECROPOLÍTICA À NOVA ORDEM DA ECONOMIA MÁXIMA}

A figura do homo sacer, originária do direito penal romano arcaico é recuperada Giorgio Agamben, caracterizada quando a vida humana é incluída no ordenamento unicamente sob a forma de sua exclusão ou absoluta matabilidade, trabalhando com o conceito "biopolítica", formulado por Foucault, uma expressão tão antiga quando a exceção soberana, quando o Estado moderno coloca a vida biológica no centro de seus cálculos, utilizando-se da técnica da "docilização", da "domesticação" dos corpos (AGAMBEN, 2002, p. 10), afirmando sua transformação em "tanatopolítica", na política a serviço da morte, da guerra, e não da vida e da paz ( Ibidem, p. 7-12).

Surgirá então "uma nova política, integramente nova, não mais fundada sobre a exceção da vida nua" (ld., p. 15), contudo, enquanto esta não surgir ainda serão atuais os exemplos do nazismo e fascismo, onde a lei autorizava a barbárie, ocasionando o que de pior poderia ocorrer, a saber, a banalização da vida pelo direito, logo, a perversão mesma do direito, ao permitir o massacre da dignidade humana, afirmando a biopolítica do totalitarismo moderno, do lado da sociedade de consumo e do hedonismo de massa (ld. $l b$.).

Segundo Agamben, a biopolítica moderna, se qualifica pelo seu conceito intrínseco de campo de concentração e por seguir a estrutura dos grandes Estados totalitários, representando a politização da vida nua no evento decisivo da modernidade, ou seja, o ingresso da zoé na esfera da polis, na esfera política, núcleo 
originário do poder soberano, ocorrendo uma transformação radical das categorias político-filosóficas do pensamento clássico.

Destarte, para o festejado A. ( $/ d$., p. 39) há no estado de natureza e no estado de exceção duas faces de um mesmo processo "topológico", pois o que era pressuposto como externo, o estado de natureza, ressurge no interior, como estado (juridicamente vazio) de exceção permanente, havendo uma zona topológica de indistinção, quando o estado de natureza e o direito, o dentro e o fora transitam um pelo outro. E continua:

(...) o espaço juridicamente vazio da exceção (...) no qual podia, portanto, acontecer tudo aquilo que o soberano julgava de fato necessário) irrompeu de seus confins espaço-temporais e, esparramando-se para fora deles, tende agora por toda parte a coincidir com o ordenamento normal (...) o que está ocorrendo na ex-lugoslávia e mais em geral, os processos de dissolução dos organismos estatais tradicionais na Europa oriental não devem ser vistos como um reemergir do estado natural de luta de todos contra todos, (...) mas antes, como o aflorar do estado de exceção com estrutura permanente (...) (Id. ibidem e nota 12).

E continua o A., em obra posterior, nos seguintes termos:

(...) ao contrário, a própria possibilidade de distinguir entre vida e direito, anomia e nomos coincide com sua articulação na máquina biopolítica. A vida pura e simples é um produto da máquina e não algo que preexiste a ela, assim como o direito não tem nenhum fundamento na natureza ou no espírito divino (...). A política sofreu um eclipse duradouro porque foi contaminada pelo direito, concebendo-se a si mesma, no melhor dos casos, como poder constituinte (isto e, violência que põe o direito), (...). Ao contrário, verdadeiramente política é apenas aquela ação que corta o nexo entre violência e direito. E somente a partir do espaço que assim se abre, é que será possível colocar a questão a respeito de um eventual uso do direito após a desativação do dispositivo que, no estado de exceção, o ligava a vida. Teremos então, diante de nós, um direito "puro", no sentido em que Benjamin fala de uma língua "pura" e de uma "pura" violência (2014, p.108 -111).

Diante do incessante avanço do que já foi definido como uma "guerra civil mundial", com motivos religiosos e econômicos que a torna, em tudo e por tudo, semelhante àquelas guerras civis que antecederam, na modernidade, a formação, como uma reação, de Estados nacionais, e na ausência de um Estado mundial correspondente à convulsionada sociedade civil mundial, o estado de exceção, 
certamente não por acaso, tende cada vez mais a se apresentar em todo lado, com intensidade variada, como o paradigma de governo dominante na política contemporânea. O que não haveria outro modo de qualificar, se não pelo oxímoro "Estado de não-direito", com seu “anti-direito" (GUERRA FILHO, 2006, p. 65 ss., p.77, passim), é a resposta imediata do poder estatal aos conflitos internos mais extremos, donde apresentar-se, paradoxalmente, como a forma legal daquilo que não pode ter forma legal, com a possibilidade aterrorizante de, a qualquer momento, qualquer um vir a ser tratado, pelos concidadãos ou agentes públicos, como os antigos romanos tratavam aqueles a quem imputavam a condição de homo sacer, como desvestido de qualquer proteção jurídica, não sendo sequer punível como homicida quem lhes tirasse a vida. O emprego constante e sub-reptício de medidas concebidas como provisórias, logo, excepcionais, enquanto técnica de governo, regular e privilegiada, termina resultando em uma indeterminação entre democracia e autoritarismo, sendo o regime nazista um caso mais agudo e a atual situação em que nos encontramos no País um exemplo, por enquanto, mais brando e recente, já motivo de grande preocupação e mostrando-se, mesmo, ameaçador, pelo nível de degradação a que se vem chegando, nessa esfera de indeterminação entre o Direito e a política.

Por sua vez, um dos mais destacados pensadores e filósofos africanos da atualidade, com seu pensamento contra hegemônico, Achille Mbembe retoma as análises de Foucault acerca da biopolítica e propõe o termo "necropolítica", em seus dois principais livros, "Crítica da razão negra" e "Necropolítica", afirmando haver um dispositivo fantasmático do poder colonizador impondo uma nova ordem de verdade. Ao haver a sujeição do nativo pelo desejo com sua função sedativa e epilética, o colonizado fica para fora se si, iludido, em um processo de travestimento e estranhamento, com a profusão de fantasmas. Ocorre a passagem do real ao fantasmático, do avesso ao direito, no racismo institucional, sendo o negro o espectro da modernidade (MBEMBE, 2018a, p. 229). O capitalismo social equivale, para ele, a uma vasta necrópole, enquanto o neoliberalismo produz a indiferença, codificando o mundo a partir de lógicas empresariais. A violência fantasmal se baseia na negação de qualquer singularidade essencial (Ibidem, p. 11, p. 234; p.250), havendo necessidade de se reabilitar a singularidade e a diferença, apontando para o devir 
negro no mundo, ante a universalização da condição negra no mundo e transformação do ser humano em dados numéricos e códigos.

Essa forma particular de terror, o necropoder seria a concatenação entre o biopoder, o estado de exceção e o estado de sítio (2018b, p. 31). A ocupação colonial tardia, contemporânea, ao contrário da primeira ocupação moderna, com sua combinação entre o disciplinar, a biopolítica e a necropolítica, seria a mais bem sucedida forma de necropolítica, a exemplo da Palestina, uma forma específica do terror, o necropoder, possibilitando a dominação absoluta sobre os habitantes do território ocupado (Ibidem, p. 41; p. 48).Trata-se da nova ordem da economia máxima, agora representada pelo massacre, criando "mundos de morte" e o estatuto de "mortos-vivos" (Ibidem, p. 71).

Verificamos nas expressões "produção de fantasmas" e "violência fantasmal" utilizadas por Mbembe, e ao propor, outrossim, uma teoria do pensamento liberta do sujeito e do objeto (MBEMBE, cit., p. 61) e o pensar o pensamento como irregularidade intensiva, dissolução do eu (Ibidem, p. 66) e propor um pensamento do afirmativo e do múltiplo, um pensamento acategórico (Ibidem, p. 69), pensando-se o fantasma e o acontecimento, uma nítida influência de Foucault, senão vejamos. Isto porque Foucault vai propor uma metafísica liberta, uma metafísica do fantasma, girando em torno do ateísmo e da transgressão, a série do simulacro libertado, com dois palcos privilegiados, a psicanálise como a prática metafísica, e o teatro multiplicado, policênico, simultaneado, fragmentado em cenas que se ignoram e se fazem sinais, sem se representar nada (FOUCAULT, 1997, p. 252). Trata-se de um novo pensamento, um pensamento genital, intensivo, afirmativo, acategórico, da filosofia como teatro de mímicas com cenas múltiplas, fugidias e instantâneas, como os gestos sem se ver ou fazer sinais, "[...] um teatro onde sob a máscara de Sócrates estala de súbito o rir do sofista (...), onde Fichte manco anuncia o eu fendido, o eu dissolvido" (Ibidem, p. 81). 


\title{
2 DESENVOLVIMENTO: ESTADO DE EXCEÇÃO, CONTRARREVOLUÇÃO JURÍDICA, VIOLÊNCIA "PURA", "DIVINA" OU "REVOLUCIONÁRIA" E BODE EXPIATÓRIO
}

Apesar de inexistir, como lembra Boaventura de Sousa Santos, uma suspensão formal do conteúdo civil e político dos direitos e garantias básicas das constituições nacionais, mas o esvaziamento destes, a exemplo das leis antiterror promulgadas em diversos países, estamos diante de uma nova forma de Estado, o estado de exceção (2010, nota 31, p. 36 e 37, p. 38), relacionando este ao conceito de "contrarrevolução jurídica", uma forma de ativismo judiciário conservador, que consiste em neutralizar, por via judicial, diversos avanços democráticos historicamente conquistados pela via política, quase sempre a partir de novas constituições (SOUSA SANTOS, 2007, p. 75; SERRANO, 2015; Id., 2016; VALIM, 2017), com reações criminalizadoras e repressivas pelos tribunais e outras instituições do sistema de justiça em face dos movimentos sociais. Neste sentido o exemplo da ação do Ministério Público do Estado do Rio Grande do Sul em 2008, propondo a dissolução do movimento MST e a decretação de sua ilegalidade, em um movimento reverso à expansão garantista do poder judicial, como a emergência de uma contrarrevolução jurídica (Ibidem, p. 75 e ss).

Relembremos, nesse passo, a "1 $1^{a}$. Tese sobre o Conceito de História" de Benjamin: ${ }^{1}$

\begin{abstract}
Sabemos de um autômato, construído para revidar lances no jogo de xadrez, de um modo que lhe garantisse a vitória sempre. Um fantoche vestido à turca, com um narguilé na boca, sentava-se diante do tabuleiro, colocado numa grande mesa. Um sistema de espelhos criava a ilusão de que a mesa era
\end{abstract}

\footnotetext{
1 "Bekanntlich soll es einen Automaten gegeben haben, der so konstruiert gewesen sei, dass er jeden Zug eines Schachspielers mit einem Gegenzuge ewidert habe, der ihm den Gewinn der Partie sicherte. Eine Puppe in türkischer Tracht, eine Wasserpfeife im Munde, sass vor dem Brett, das auf einem geräumigen Tisch aufruhte. Durch ein System von Spiegeln wurde die Illusion erweckt, dieser Tisch sei von allen Seiten durchsichtig. In Wahrheit sass ein buckliger Zwerg darin, der ein Meister im Schachspiel war und die Hand der Puppe an Schnüren lenkte. Zu dieser Apparatur kann man sich ein Gegenstück in der Philosophie vorstellen. Gewinnen soll immer die Puppe, die man 'historischen Materialismus' nennt. Sie kann es ohne weiteres mit jedem aufnehmen, wenn sie die Theologie in ihren Dienst nimmt, die heute bekanntlich klein und hässlich ist und sich ohnehin nicht darf blicken lassen". (G.S. I-2, p. 693). Tradução [manuscrito] de J.M. Gagnebin e M. Lutz-Müller.
} 


\begin{abstract}
visível por todos os lados. Na realidade, um anão corcunda se sentava nela, um mestre enxadrista, e dirigia com cordéis a mão do fantoche. A este aparato pode-se imaginar uma contrapartida na filosofia. A vitória seria sempre do boneco que chamamos 'materialismo histórico'. Ele pode confrontar-se, sem problema, com qualquer adversário, desde que tome como serva a teologia; hoje, sabidamente, pequena e feia, não devendo deixar-se ver de jeito nenhum.
\end{abstract}

O que Benjamin deixa aí transparecer do que percebeu com toda clarividência, ao escrever isso em seus apontamentos finais - então prestes a pôr fim à própria vida, em face do cerco nazista -, agora está ofuscantemente claro, diante de nós. $E$ isso, note-se, não deve nos levar a considerá-lo como profeta inspirado misticamente, mas tão-somente como alguém dotado da hiper-lucidez dos grandes filósofos, que lhes permite perceber no presente o que a maioria precisará de muito mais tempo para se dar conta, em seu futuro. E aos comentadores, seguidores, pósteros, como o é Agamben para Benjamin, resta a tarefa de desfazer o ofuscamento, mostrando-nos o que se revelara a seus avatares.

A teologia cristã, desenvolvida ao longo de séculos, pondo a seu serviço a filosofia grega (philosophia serva theologiae), forjou ideologicamente a modernidade, assim como a política eclesiástica "católica apostólica romana" - uma vez adotada a religião cristã pelo Império romano periclitante, a fim de, assim, escapar, pelo menos no lado oriental, de sua crise de legitimidade, dada a perda de seu fundamento religioso - irá produzir o modelo jurídico (o Estado) e econômico (o capitalismo) adotados modernamente. E é essa teologia, pequena e feia, que se mostrou tanto mais eficaz, quanto menos se deixou ver, uma vez revelada sua feiura e pequenez, pela luz da razão, passando a fazer-se presente em todas as diferentes versões da ideologia moderna, inclusive aquelas de matriz marxista, com seu determinismo histórico e messianismo da volta do estado primitivo paradisíaco, preconizando o advento, futuro e certo, do comunismo.

Não é de estranhar, portanto, que Benjamin receasse a publicação das suas "Teses", temendo ser vítima da incompreensão de seus próprios pares, como segredou na correspondência em que as encaminhou a Greta Adorno, esposa do filósofo - um dos que teriam dificuldade de entendê-lo? Explica-se assim o expediente de enviar o texto através de mãos femininas? E dentre os obstáculos ao bom 
entendimento estaria justamente o problema trabalhado no texto que o leitor tem às mãos, a saber, a incompreensão de ser o tempo messiânico ou a concepção messiânica do tempo o pano de fundo das teses que Benjamin nos legou como testamento, tanto que assim foram recebidas por Derrida (v. DERRIDA, 2007; GUERRA FILHO, 2006, p. 75 ss.), embora enfatizando o que nas "Teses" aparece como a oitava, e que toca mais diretamente com a filosofia (política) do direito, à qual aludirei adiante, ao final. No momento, cabe indicar a prolongada influência secreta da teologia, o que se coloca como tarefa primordial a ser estudado, para os que se interessam por entender os tempos em que vivemos e, então, saber como intervir para favorecer a redenção, a revolução, em detrimento da danação, da destruição humana do mundo, humano e natural, com a qual nos deparamos hoje.

$\mathrm{O}$ anão corcunda, pequeno (mesquinho) e feio, que lembra em sua descrição o mais feio dos homens, o último homem do universo nietzscheano, apresenta-se a público agora, desavergonhadamente, por exemplo, fazendo uma nova cruzada contra a vida, enquanto bíos, em nome da vida, enquanto zoé, vida nua, como a define Agamben, dentro do projeto Homo Sacer, aquela que sobra aos que foram desvestidos de uma qualquer forma humana de viver, nós, os ameaçados constantemente pelo estado de exceção permanente em que vivemos, nas atuais ameaçadoras condições de vida no planeta.

De acordo com outra das "Teses sobre o Conceito de História", de Benjamin, a These VIII, temos que:

\begin{abstract}
A tradição dos oprimidos nos ensina que o 'Estado de exceção', no qual vivemos, é a regra. Devemos chegar a um conceito de história que esteja à altura dele. Aí nossa tarefa será expor diante de nossos próprios olhos o efetivo Estado de exceção; e por este meio melhoramos nossa posição na luta contra o fascismo. ${ }^{2}$
\end{abstract}

\begin{abstract}
${ }^{2}$ No original: "Die Tradition der Unterdrückten belehrt uns darüber, daß der 'Ausnahmezustand', in dem wir leben, die Regel ist. Wir müssen zu einem Begriff der Geschichte kommen, der dem entspricht. Dann wird uns als unsere Aufgabe die Herbeiführung des wirklichen Ausnahmezustands vor Augen stehen; und dadurch wird unsere Position im Kampf gegen den Faschismus sich verbessern. Dessen Chance besteht nicht zuletzt darin, daß die Gegner ihm im Namen des Fortschritts als einer historischen Norm begegnen. - Das Staunen darüber, daß die Dinge, die wir erleben, im zwanzigsten Jahrhundert 'noch' möglich sind, ist kein philosophisches. Es steht nicht am Anfang einer Erkenntnis, es sei denn der, daß die Vorstellung von Geschichte, aus der es stammt, nicht zu halten ist".
\end{abstract}


Aqui vale lembrar um exemplo paradigmático, seguindo análise feita por Schmitt em seu opúsculo "Legalidade e Legitimidade", de 1932, cuja tese central era a de que se fazia muitas vezes necessário sair da legalidade para entrar na legitimidade, em direito (SCHMITT, 1985; GUERRA FILHO, 2007, p. 237 ss.). O último tópico da segunda parte ou capítulo do texto de Schmitt mostra como a prática política e jurídica instaurou na Alemanha um terceiro "legislador extraordinário", "ratione necessitatis": o Presidente do Reich e seu governo. O ensejo para tanto foi dado pela norma da segunda parte do art. 48 da Constituição, que dava poderes ao Presidente para adotar medidas necessárias à restauração da segurança e da ordem pública, quando estivessem gravemente ameaçadas, valendo-se para isso, se necessário, das forças armadas, bem como suspendendo, temporariamente, o exercício, total ou parcial, de direitos fundamentais, cabendo ao Parlamento (Reichtag), ao ser informado, derrogar referidas medidas - em se dando a necessária maioria, bem entendido. Eis o que se pode chamar, em termos metafóricos e atuais, uma espécie de "medida provisória constitucional". O quadro descrito por Schmitt vai então se assemelhar bastante àquele de nosso País, quando por tolerância dos tribunais, especialmente de nossa mais alta Corte, conivência dos poderes políticos e respaldo da doutrina constitucional majoritária, disposições normativas oriundas do executivo se substituem às leis, ainda que, em princípio, provisoriamente, e para resolver situações específicas. Estabelece-se, assim, no lugar antes ocupado pela lei, medidas "com força de lei", mas que não possuem os traços mais típicos das leis, como a generalidade, abstratividade e durabilidade. Premidos pelas circunstâncias a também reagir com maior celeridade e resolver situações pontuais, o próprio legislador passa a editar "medidas legislativas", e então dá margem a que o titular do executivo, agora com feições já ditatoriais, se afirme cada vez mais como autoridade competente para legislar, extraordinariamente.

O estado de exceção não é uma ditadura, mas um espaço vazio de direito. $\mathrm{Na}$ Constituição romana, como nos relembra em sua obra de último citada Agamben, o ditador era uma figura específica de magistrado que recebia seu poder de uma lei votada pelo povo. Ao contrário, o "iustitium", assim como o estado de exceção moderno, não implicaria a criação de nenhuma magistratura nova, mas unicamente a 
de uma zona de anomia na qual todas as determinações jurídicas são desativadas. De resto, a despeito do que se costuma afirmar, Hitler não pode ser considerado, a rigor, como um ditador, pois era o chanceler do Reich, legalmente nomeado pelo presidente. $\mathrm{O}$ que caracterizou o regime nazista - e torna também seu modelo tão perigoso, como alerta Agamben - é que ele deixou subsistir a Constituição de Weimar, tida como a mais avançada de seu tempo, acrescentando-lhe uma outra ordem (ou "desordem") jurídica, juridicamente não-formalizada, que só podia subsistir ao lado da primeira graças à generalização do estado de exceção. Não se estaria fazendo o mesmo, já há tempos, também entre nós, com a balzaquiana Constituição de 1988 ? Esse espaço vazio de direito parece, por uma razão ou outra, tão essencial à própria ordem jurídica que esta última deve tentar por todos os meios assegurar uma relação com o primeiro, como se, para garantir seu funcionamento, o direito devesse necessariamente manter uma relação com uma anomia. É precisamente nessa perspectiva, segundo Agamben, que devemos ler o debate que opôs, de 1928 a 1940, Walter Benjamin e Carl Schmitt, sobre o estado de exceção (Cf. SOUZA, 2018, p. 3538; HEIL, 1996; WILDE, 2008).

Considera-se geralmente que o ponto de partida do debate é a leitura que Benjamin fez da "Teologia Política" de Schmitt, em 1923, bem como o conjunto das citações da teoria da soberania de Schmitt em sua malograda tese de livre-docência sobre o "Drama Barroco Alemão" (Trauerspeil), sendo ainda de se destacar como fundamental a posição schmittiana da soberania como uma resposta à crítica que Benjamin faz da violência ("Crítica da Violência/do Poder - Gewalt").

Giorgio Agamben na obra "Estado de Exceção" retoma os desenvolvimentos devidos a pensadores tão distintos, no espectro ideológico, como são Carl Schmitt e Walter Benjamin, a respeito de um tema que se apresenta como uma antinomia, geralmente evitada pelo pensamento formalista reinante no Direito, o qual não estaria preparado sequer para percebê-lo. Demonstração cabal do que se vem de afirmar é dada pelo modo como a revolução vem considerada por teoria que leva os pressupostos formalistas às suas últimas consequências, como é o caso daquela kelseniana (VILANOVA, 1981, p. 59 ss.), em conexão com uma perspectiva que se descortina, de reação possível e proporcional a essa situação-limite a que 
chega o Direito em tais circunstâncias, mesmo no âmbito de um Estado, formalmente, de Direito e Democrático, qual seja, a do exercício de um direito fundamental à revolução, à ruptura da ordem que se desconstitucionalizou, mesmo que continue vigorando, sem o mínimo de eficácia, uma Constituição exemplar.

Trata-se, para ele, de estabelecer a possibilidade de uma violência no exterior ou além do direito, de uma violência que possa, enquanto tal, romper a dialética entre a violência que instaura e a que conserva a lei. Essa outra violência, Benjamin chamaa "pura", "divina" ou "revolucionária". Daí afirmar, com base em Benjamin, haver uma alternativa entre uma violência, inevitável, que põe (e produz) o Direito, sacra, e aquela outra, nefasta, que o conserva: a violência fora do Direito, uma violência divina, que faz justiça (Cf. 2004, p. 84 s.). Por sua vez, René Girard, em "A Violência e o Sagrado", afirma que só o sacrifício do "bode expiatório" pode catalisar a violência de todos contra todos, gerada pelo desejo mimético que acomete o ser humano, desejando o desejo do outro, por não saber por que e o que deseja. Os "bodes expiatórios" são exemplos dos excluídos/incluídos das sociedades modernas, como os que se acham internos e internados, em domicílios, reformatórios, asilos, delegacias, prisões, hospitais e também naquela instituição paradigmática dessas todas, segundo Giorgio Agamben, que é o campo de concentração, para refugiados ou prisioneiros em geral, com status indefinido. Enquadram-se em tal conceito todos aqueles na condição de morto-vivo, ressaltando-se a afirmação de Slavoj Žižek de que todos nós somos na atualidade "homo sacer" (2017), já que ninguém está realmente imune - de uma mera denúncia, ou de sermos assassinados, sem mais, sem sequer ser considerada tal conduta como criminosa. Tal possibilidade vislumbra-se claramente em estados de exceção, de forma exemplar em regimes ditatoriais, quando qualquer um pode vir a ser vítima de alguma denúncia anônima.

O que a lei não pode suportar, o que ela sente como uma ameaça intolerável, é a existência de uma violência que lhe seja exterior, ao contrário da violência (Gewalt) que vem de dentro do direito mesmo, do aparato institucional (Gewalt), e isso não apenas porque suas finalidades são incompatíveis com os fins da ordem jurídica, mas pelo "simples fato de sua exterioridade". Compreende-se agora em que sentido a doutrina schmittiana da soberania pode ser considerada uma resposta à crítica de 
Benjamin. O estado de exceção é precisamente o espaço no qual Schmitt tenta capturar e incorporar a tese de uma violência pura existindo no exterior da lei. Para Schmitt, não existe nada como uma violência pura, não há violência absolutamente exterior ao "nomos", porque, com o estado de exceção, a violência revolucionária já se encontra incluída no direito.

O estado de exceção seria, portanto, o artifício empregado por Schmitt para responder à postulação por Benjamin de uma violência pura. A palavra final de Benjamin na polêmica com Schmitt estaria na já referida oitava das "Teses sobre o Conceito de História", texto que deixa como uma espécie de testamento, concluído pouco antes de seu suicídio.

Benjamin reformula a posição para voltá-la contra Schmitt: uma vez cessada qualquer possibilidade de um estado de exceção fictício, no qual a exceção e a regra são temporal e localmente distintas, o que é doravante efetivo é o estado de exceção no qual vivemos, em que não poderíamos mais distinguir a exceção da regra. Aqui, assinala Agamben, toda ficção de um vínculo entre violência e direito desaparece: não há mais que uma zona de anomia em que prevalece uma pura violência sem nenhuma cobertura jurídica. E é nesse estado de cobertura fantasmagórica que nos encontraríamos em nosso "País do Carnaval", donde de repente o Carnaval passar a incomodar tanto a quem não deseja que se revele a montagem pseudo-jurídica sob a qual se camuflam para exercer violentamente o poder.

A proximidade estrutural entre o direito e a anomia, entre a pura violência e $o$ estado de exceção, possui também, como sucede com frequência, uma figura invertida. Os historiadores, etnólogos e especialistas do folclore estão acostumados a festas anômicas, como as saturnais romanas, o charivari e o Carnaval da Idade Média, que suspendem e invertem as relações jurídicas e sociais que definem a ordem normal. Os patrões se põem a servir seus criados, os homens se vestem e se comportam como animais, os maus costumes e os crimes que seriam punidos pela lei são de repente autorizados.

O folclorista Karl Meuli, segundo Agamben (2004, p. 109), teria sido o primeiro a sublinhar o vínculo entre essas festas anômicas e as situações de suspensão do direito que caracterizam certas instituições penais arcaicas. Nelas, como no 
"iustitium", quando o direito ficava suspenso tal como o sol no "solisticium", pode-se matar um homem sem processo, destruir sua casa ou apoderar-se de seus bens. Longe de reproduzir um passado mitológico, a desordem do Carnaval e as destruições tumultuosas do Charivari reatualizariam uma situação histórica real de anomia.

O vínculo ambíguo entre o direito e a anomia é assim plenamente evidenciado: o estado de exceção é transformado numa festa sem restrição, na qual se exibe a violência pura para que se usufrua dela em toda a liberdade. Assim, o sistema político do Ocidente parece ser uma máquina dupla, como também propõe Roberto Esposito (2013), isto é, fundada sobre a dialética entre dois elementos heterogêneos e, de certo modo, antitéticos: o "nomos" e a anomia, o direito e a violência pura, a lei e as formas de vida, cuja articulação o estado de exceção tem por vocação garantir. Enquanto esses elementos permanecem separados, sua dialética pode funcionar, mas quando eles tendem à indeterminação recíproca e a coincidir num poder único de duas faces, quando o estado de exceção se torna a regra, então o sistema político se transforma num aparelho de morte ("tanatopolítica"), como temos assistido, estarrecidos, ocorrer em nosso País.

Passamos a tecer algumas considerações no tocante ao estudo das questões que vem aqui nos ocupando por parte do distinguido professor de filosofia da UNICAMP, especialmente por expor e analisar o pensamento de Nietzsche, com relação à figura do banido, do proscrito (der friedlose), a qual possui semelhança com a figura do homo sacer, chegando a afirmar que Agamben, embora não se refira diretamente ao texto de Nietzsche da Genealogia da moral, teria se fundamentado em tal filósofo, tanto no desenvolvimento sobre o homo sacer, como naquela figura correlata que é a do "estado de exceção" (2013, p. 91), apontando, outrossim, para a superficialidade do humanitarismo das declarações de direitos fundamentais, que seriam como máscaras da realidade da dominação existente, senão vejamos.

Segundo Nietzsche, em "Genealogia da Moral III" (GIACOIA, 2013, p. 23), o homem é um animal doente, o mais doente entre todos os animais, e sua patologia consiste num paradoxal querer o nada, relacionado à renúncia de si, ao abandono do mundo e demais ideais ascéticos, que interpretam o sofrimento, consequência da culpa, como via para sua salvação. O homem possuiria uma vontade vingativa, 
ressentida, derivada de seu complexo de culpa, e estes seriam a medula espinhal da humanidade. Haveria, então, um ódio ao que é humano e ao que é animal, o medo da felicidade e da beleza. A solução segundo o A. seria a superação da culpa e do ressentimento com o além-do-homem, um novo começo do devir-homem.

Haveria, no entender de Giacoia, uma afinidade profunda entre o sacrifício e o sagrado, já que pelos ritos cerimoniais das oferendas se estabeleceria uma relação entre tais conceitos, (ld. ib., p. 35-36) possuindo as expressões sacer, e sanctus, uma dupla face, uma positiva, a presença divina, e o negativo, aquilo que está proibido ao contato dos homens. Sacer, no seu entender, origina-se da expressão "sacrificar" (do latim mactare, significando sacrificar um animal), significando "levar à morte", "tornar sagrado", e da relação mencionada entre sacrifício e sagrado, sacrifício e morte. O sacrifício vitimário, seu rito e seu culto reuniriam o sacrifício e o sagrado. A violência sacrificial seria a origem da sociabilidade primitiva, (ld. ib., p. 36-39) relembrando René Girard acerca do assassinato fundador da sociedade, segundo o qual o sacrifício impede a expansão da violência, auxiliando os homens no controle da vingança. $O$ sacrifício visa a eliminação da violência por meio da própria violência, sendo esta a origem fundadora, segundo Giacoia, com apoio em Girard, das instituições judiciárias. O sacrifício implicaria a repetição de uma violência, mantendo-se pela memória, ou seja, o jurídico brotaria do sagrado. Também a origem da responsabilidade e com ela da culpa originam-se do sacrifício, da violência sacrificial (ld. ib., p. 72 ss.).

Há na noção de sacrifício a busca da equivalência, do equilíbrio perdido, de uma compensação, através da restituição da vida pela vida.

Passa então o A. sob comento à análise da violência e do Direito, afirmando a violência como geradora do Direito e do Estado (ld. ib., p. 45 - 52) na esteira de Nietzsche, segundo o qual não existe direito que em seu fundamento não seja pretensão, usurpação de um ato de violência. O homem, em tais circunstâncias, já não é mais pessoa mas, simples engrenagem, dissimulado, fragmentário e escravizado, sem ter sequer a posse de si mesmo, havendo assim um apequenamento do homem. Entende Giacoia que para Nietzsche a violência se institui como fato jurídico primordial, afirmando que com a violência dos dominadores principia o Estado, na esteira novamente de Nietzsche. Ambos refutam, portanto, a 
tese da origem da socialidade humana pelo contrato social. Portanto, segundo Giacoia, quanto à origem da sociedade e da socialidade humana, "a violência soberana não é na verdade fundada sobre um pacto, mas sobre a inclusão exclusiva da vida nua no Estado" (Id. ib., p. 113).

Giacoia se aproxima então dos conceitos formulados por Agamben, ao afirmar que as situações de direito nunca podem ser mais do que situações de exceção, e que a dominação somente pode se fixar na moldura de um ritual regrado, com direitos e obrigações, bem como identificando Justiça com equidade, em razão dos procedimentos e sistemas de compensação nas comunidades pré-estatais; a justiça teria sua origem no instituto do bando, segundo Nietzsche, ao analisar a obra de Rudolph von Jhering, (ld. ib., p. 77-81) aproximando os institutos da proscrição germânica e da sacratio do direito romano arcaico.

Com clara influência novamente de Nietzsche o A. estabelece então uma correspondência entre o sacer romano, a sacratio romana arcaica e o banido, pois ambos estariam condenados a viver em estado de proscrição religiosa e civil, excluídos da comunidade e sujeitos à vingança divina, vistos como inimigos. Afirma que seriam irmãos o sacer e o banido, e que ambos poderiam ser mortos independente de um juízo e fora do Direito (Id. ib., p. 83).

Banido possui relação com bandido, e em alemão os termos Bande e Bann significam ao mesmo tempo a expulsão da comunidade e a insígnia do governo soberano. Banido na antiguidade germânica é retratado pela expressão friedlos, "o sem paz", que poderia ser morto por qualquer um, sem configurar homicídio. Retrata, também que Agamben teria se inspirado em Nietzsche ao tratar o soberano como o lobisomem, ${ }^{3}$ o homem lobo do homem, correspondendo à expressão "besta-fera", utilizada por aquele, o qual, por sua vez, a teria colhido em Rudolph von Jhering (Cf. GUERRA FILHO, 2013, p. 84 ss.). A expressão, der friedlose, literalmente "o sem

3 Como também se faz notar em Derrida, no seu último seminário, justamente intitulado The Beast and the Sovereign, 2009. É que ambos estão sob a influência do que um arguto teórico do direito norte-americano caracterizou como "o espectro de Nietzsche", ao qual poderíamos também acrescentar um outro, mais próximo: o de Heidegger. Cf. Adam Thurschwell, 2002. 
paz", o homem de fora, o proscrito, é retratada por Nietzsche (Genealogia da Moral, II, 9), ao mencionar a relação do credor com seu devedor.

Sacer seria o homem desumanizado, impuro, maldito, tornado tal em consequência de uma condenação pelo delito cometido de desonra aos deuses. Segundo Jhering (1942, p. 201, apud ld. ib., p. 82. Id. ib. e p. 90), seria um ato de mérito Ihe tirar a vida, dispondo no mesmo sentido Giacoia: "ser sacersignificava estar proscrito tanto da comunidade religiosa como da civil, no período da vida pré-social, razão pela qual sua morte nem poderia ser considerada expiação ou sacrifício (...)". Trata-se, portanto, da figura excluído-incluído, por meio de sua própria suspensão, tal como trabalhado por Agamben em sua obra Homo sacer. E continua Giacoia comparando as expressões bann e homo sacer (ld. ib. e p. 90):

(...) ○ bann (bando) resulta, pois de uma transposição da matriz jurídicoobrigacional do débito e do crédito, ampliando, aprofundando e desenvolvendo o sentimento primitivo de Justiça como equivalência. (...) o homo sacer apresentaria a figura originária da vida presa no bando soberano e conservaria a memória da exclusão originária através da qual se constitui a dimensão política.

Os seres humanos não podem ser mais tidos como doenças e doentes, devem ser retratados como uma promessa e não como uma ameaça, e neste sentido, a esperança de assim modificarem a sua relação consigo mesmo, com os outros e com a Natureza, a fim de mudar sua autoconsciência e tal visão.

Roberto Esposito, por sua vez, em sua obra Bios - biopolítica e filosofia, a partir principalmente de Foucault, Hobbes, Hegel, Heidegger, Peter Sloterdijk, Tocqueville (imunização da liberdade) e igualmente de Nietzsche, trabalha intensamente a questão da biopolítica e do biopoder, bem como da transição entre o direito de soberania, considerando tal transição, notoriamente apontada por Foucault como indo do "fazer morrer ou deixar viver" para o "poder de fazer viver e deixar morrer".

Esposito considera que a questão da imunização do corpo político foi trabalhada primeiramente por Hobbes, encontrando neste autor seu protótipo (Ibidem, p. 75), mas, em uma elaboração inconsciente, irrefletida, e posteriormente por Hegel 
(ao afirmar o negativo como o motor da realização do positivo), já em uma elaboração mais consciente, porém mais precisamente por Nietzsche, por sua elaboração de forma plenamente consciente (ld.ib), pois com sua obra a imunização passa a estar completamente elaborada (Ibidem, p. 76).

O A. ao mesmo tempo que em alguns pontos ressalva a importância da análise foucaultiana e a elogia, em alguns outros pontos critica Foucault por ter deixado um elo ausente entre biopolítica e modernidade, justamente representada pela imunidade (Ibidem, p. 24) entendendo ser insuficiente sua teoria, e que teria deixado em branco uma pergunta decisiva: "se a vida é mais forte do que o poder que no entanto a assedia, se sua resistência não se deixa vergar pelas pressões dele, como é que o resultado a que a modernidade chega é a produção em massa da morte?" (Ibidem, p. 63). Critica, outrossim, sua análise no tocante à bifurcação em direções divergentes ao tratar do efeito da biopolítica (Ibidem, p. 54), afirmando: “(...) mais uma vez a categoria de biopolítica se volta a fechar sobre si própria sem revelar o conteúdo do seu enigma" (Ibidem, p. 55). E complementa dispondo que "estamos talvez no ponto de máxima tensão - mas também de potencial fratura interna - do discurso foucaultiano" (Ibidem, p. 68). Continua em seguida com as críticas afirmando não ter Foucault desenvolvido de forma completa o conceito de política e de vida, bem como tendo-Ihe escapado o paradigma da imunização (Ibidem, p. 73):

(...) o autor nunca articulou suficientemente o conceito de política - ao ponto de sobrepor substancialmente as expressões de biopoder e de biopolítica. Mas a observação análoga - de falhada ou insuficiente elaboração conceitual se poder também fazer a propósito do outro termo da relação, ou seja, o da vida (...) (lbidem, p. 54).

O A. em exame comenta sobre o uso de Agamben dos termos bios, como vida qualificada, e zoé, como vida biológica, ${ }^{4}$ vida simplesmente, mas acrescenta um outro termo entre estes, techné, afirmando que o corpo atualmente é atravessado pela

${ }^{4}$ A distinção proposta por Agamben é severamente criticada por Derrida, 2009, p. 315 ss. Afinal, em 0
animal que logo sou (A seguir), trad.: Fábio Landa, 2002, p. 49, Derrida já havia proposto a hipótese
da vida ser uma "(... experiência na qual se abalam os limites à passagem de fronteiras entre bios e
zoê, biológico, zoológico e antropológico, como entre vida e morte, vida e técnica, vida e história etc.)". 
técnica (Ibidem, p. 31) e que entre os termos bios e nomos, "vida" e "política", que constituem a expressão biopolítica, se verifica o paradigma da imunização (Ibidem, p. 73). Esposito conceitua biopolítica de forma negativa, entendida como não soberania, havendo uma cesura nítida e irreversível entre ambas, ao passo que conceitua imunidade como sendo a relação que liga a vida ao poder, sendo ao mesmo tempo o poder de conservação da vida (Ibidem, p. 74). Imunização é vista como uma proteção negativa da vida, e pressupõe aquilo que, no entanto, nega (Ibidem, p. 81).

Retoma o A., outrossim, Heidegger, sustentando que este como ninguém observou o fenômeno da imunidade, ao afirmar na célebre palestra a ascensão da "imagem do mundo" (Weltbild) como o que na modernidade é a época da representação, na medida em que a passagem "do subjectum que se coloca como ens in se substantialiter completum perante seu objeto significa reconduzi-la filosoficamente ao horizonte da imunização". Afirma que Heidegger seria o único com condições de dirigir o confronto filosófico com a biopolítica (Ibidem, p. 218), mas concluindo ao final que também este deixara fechada a caixa preta da biopolítica (Ibidem, p. 223; p. 227), justamente por não abordar o conceito de carne, falhando no que se refere à análise do bios, ao contrário da análise de Merleau-Ponty. E continua:

(...) mas ligar o sujeito moderno ao horizonte da segurança imunitária significa reconhecer a aporia em que sua experiência fica presa: a de procurar 0 refúgio da vida nas mesmas potências que impedem o seu desenvolvimento (Ibidem, p. 88, p. 220-221). (...) a simetria do contraste entre Heidegger e a biopolítica nazi não acaba aqui. Tanto o primeiro como a segunda consideram vida e existência ligadas por uma relação exclusiva - no sentido de que uma é definida pelo seu não estar à altura da outra - mas a diferença em ambos os casos é constituída pela experiência da morte. É aqui justamente, no entanto, que as duas perspectivas divergem definitivamente. Enquanto na tanatopolítica nazi a morte representa o pressuposto, antes ainda do que o destino, da vida esvaziada de potência biológica e por isso reduzida a mera existência -, para Heidegger ela é o modo de ser próprio de uma existência diferente da vida nua. (...) enquanto na primeira a estrutura soberana do biopoder está na possibilidade de submeter qualquer vida ao crivo da morte, para o segundo a vocação da morte constitui a forma originalmente política em que a existência se decide em qualquer coisa que está sempre para além da simples vida (Ibidem, p. 146).

Esposito se coloca como contrário à existência de uma norma fundamental ou de um critério normativo com base no qual se estabeleceriam medidas de exclusão, 
(Ibidem, p. 263-264) e termina comentando sobre Deleuze, que no seu entender, teria antecipado a figura da biopolítica afirmativa, analisando o último texto deste, denominado L'ímmanence: une vie (Philosophies n. 47, 1995) e o já clássico Logique du sens (1969). In verbis:

(...) qualquer vida é forma de vida e qualquer forma se refere à vida. Não é este o conteúdo nem o sentido último da biopolítica. Mas é pelo menos o seu pressuposto: se mais uma vez vai ser renegado numa política de morte, ou vai ser afirmado numa política de vida, dependerá também do modo como o pensamento contemporâneo siga as suas pistas (Ibidem, p. 273).

\section{CONCLUSÃO}

Neste ponto, completamos o enredo de nossa proposta, pois é justamente a respeito da degradação da vida em forma de morte, em nosso tempo, que Foucault sugere, em termos políticos, se deva entender a soberania - o exercício bem engendrado das relações de dominação e poder -, a saber, como fórmula do fazer morrer e deixar viver. Pensar a questão da biopolítica como imunologia e a transformação desta em tanatopolítica, depois em necropolítica, como expressão máxima da doença do homem, ou mesmo, da doença que é o homem para o ambiente em que vive e como um vírus ameaça destruir, destruindo-se também, exige que se explicite a autoimunidade do direito (GUERRA FILHO, 2014a; Id., 2014b, p. 7 - 25; CANTARINI, 2017b), pois é nosso dever maior no momento compreendermos e projetarmos outros possíveis rumos para sua infeliz ocorrência, nos quadros de uma teoria que seja, também, poética (Cf. GUERRA FILHO, 2015; 2017; CANTARINI, 2017a). Conclui-se, com fulcro nos estudos de Roberto Esposito que a biopolítica é imunização, havendo uma absoluta coincidência entre ambos, ocorrendo a progressiva indistinção entre norma e exceção, por uma absoluta identificação dos opostos e a multiplicação exponencial dos riscos que se pretendia evitar, ou seja, pelo excesso de defesa, como no que ocorre com a doença autoimunitária, autoimunidade no sentido trabalhado pioneiramente por Jacques Derrida, em seu texto contido na obra coletiva, que ele organizou, sobre a religião. A questão que se coloca, então, é 
de como sobreviveria o sistema social global, que é a sociedade mundial, diante de um ataque por componentes dele mesmo, como para alguns ocorreria no setor financeiro do sistema econômico, diante do excesso de especulação, ou de cidadãos que ao invés de participarem politicamente por meio do voto optam por protestos cada vez mais violentos, ou quando pessoas se tornam suspeitas e, mesmo, praticantes do que se vem qualificando como terrorismo, sendo destratados como portadores de direito, na situação descrita por Giorgio Agamben com a figura do antigo direito penal romano do homo sacer, que é, como vimos, a de uma vida puramente biológica e, enquanto tal, matável sem mais. Eis como o sistema (jurídico) imunológico da sociedade, como o concebe Niklas Luhmann, pode ser confrontado com um problema similar ao de um organismo que sofre de uma disfunção autoimune. A autoimunidade é uma aporia: aquilo que tem por objetivo nos proteger é o que nos destrói. O paradoxo da autopoiese do direito terminando em autoimunidade revela o paradoxo da inevitável circularidade do Direito e suas raízes políticas nas constituições.

Como nós aprendemos de uma recente contribuição para o pensamento social de um estudioso de Luhmann e Baudrillard, conjuntamente: "A persistência da forma-binária somente pode ser assegurada pela produção dosada de algum 'outro'simulado, não mais disponível em sua forma "natural'". Se é assim, tenhamos esperança na vinda no sistema societário mundial de um vírus como o da AIDS, i.e., que desenvolva uma doença autoimune para acometer o sistema imunológico e assim impedindo que continue atacando partes do próprio organismo que deveria proteger: um vírus que realmente ajude a dar fim à sociedade desumana e ao nosso vínculo ambíguo (o double bind de Gregory Bateson) de amor/ódio com a natureza e o radicalmente outro, diverso. De outro modo, o sistema jurídico em escala global irá crescentemente reagir contra a diversidade e em fazendo isso irá minando os fundamentos mesmos da ambiência natural e cultural, humana. $E$ isso é o pior a que o recrudescimento da presente crise pode nos levar. Havemos, então, de superar as doenças autoimunes que nos acometem enquanto corpo social mundial, nos termos de Roberto Esposito, das quais a atual "crise alérgica" da União Europeia é um exemplo claro e menos grave do que aquele da Alemanha nazista, analisada por este autor, em que a enfermidade decorre da tentativa de isolamento dos contatos que 
põem a política a serviço da vida e não a vida a serviço de uma política mortífera, ou seja, da biopolítica transformada em tanatopolítica.

\section{REFERÊNCIAS}

AGAMBEN, Giorgio. Homo sacer I: o poder soberano e a vida nua, trad. Henrique Burigo, 2a․ ed., Belo Horizonte: Editora UFMG, 2002.

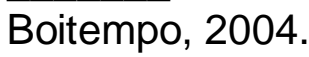

Estado de Exceção - Homo sacer II, trad.: Iraci D. Poleti, São Paulo:

. Pilatos e Jesus. Tradução Selvino Asmann, São Paulo: Boitempo editorial, 2014.

BENJAMIN, Walter. Gesammelte Schriften, vol. I, 2, Rolf Tiedemann; Hermann Schweppenhäuser (eds.), Frankfurt am Main: Suhrkamp, 1991.

CANTARINI, Paola. Teoria Erótica do Direito, Rio de Janeiro: Lumen Juris, 2017a.

. Princípio da Proporcionalidade como Resposta à Crise Autoimunitária do Direito. Rio de Janeiro: Lumen Juris, 2017b.

CAPOVIN, René. "Baudrillard as a Smooth Iconoclast: the Parasite and the Reader", in: International Journal of Baudrillard Studies, vol. 5, \# 1, 2008.

DERRIDA, Jacques (org.). A Religião, trad.: Roberta Barni e Luciano Vieira, Florianópolis: Estação Liberdade, 2000.

. O animal que logo sou (A seguir), trad.: Fábio Landa, São Paulo: EDUNESP, 2002.

Força de Lei : o fundamento místico da autoridade, trad.: Leyla Perrone-Moisés, São Paulo: Martins Fontes, 2007.

. The Beast and the Sovereign, 2 vols., Geoffrey Bennington (ed.), Chicago/Londres: The Chicago University Press, 2009.

ESPOSITO, Roberto. Bios - biopolítica e filosofia. Lisboa: Edições 70, 2004.

. "Filosofia e Biopolítica”, in ethic@, vol. 9, n. 2, Florianópolis, 2010.

. Due. La macchina de la teología política e il posto del pensiero, Einaudi: Torino, 2013. 
FOUCAULT, Michel. Nietzsche, Marx, Freud. Theatrum Philosophicum, trad.: Jorge Lima Barreto, São Paulo: Princípio, 1997.

GIACOIA JÚNIOR, O. Nietzsche: o humano como memória e como promessa. $2^{\mathrm{a}}$. ed., Petrópolis: Editora Vozes, 2013.

GIRARD, René. A violência e o sagrado, tradução: Martha Conceição Gambini, São Paulo: Editora Universidade Estadual Paulista (EDUNESP), 1990.

GUERRA FILHO, Willis S. "(Anti-)Direito e força de lei/ lei", in: Panóptica, ano 1, n. 4, 2006 (disponível em: https://pt.scribd.com/document/79376966/Anti-Direito-WillisSantiago).

. Teoria Processual da Constituição, 3a. ed., São Paulo: RCS, 2007.

. Teoria da Ciência Jurídica, 2a. ed., São Paulo: Saraiva, 2009.

. "Potência crítica da ideia de direito como um sistema social autopoiético na sociedade mundial contemporânea", in: Jurisdicização das Esferas Sociais e Fragmentação do Direito na Sociedade Contemporânea, Germano Schwartz (org.), Porto Alegre: Livraria do Advogado, 2012.

. "Luhmann and Derrida: Immunology and Autopoiesis", in: Luhmann Observed: Radical Theoretical Encounters, A. La Cour e A. PhilippopoulosMihalopoulos (eds.), Londres/Nova York: Palgrave, 2012.

. CARNIO, Henrique Garbellini. Teoria Política do Direito. A expansão política do direito, 2a․ ed., São Paulo: RT, 2013.

Immunological Theory of Law, Saarbrücken: Lambert, 2014.

. "A Crise Autoimunitária da Nova Ordem Internacional" in Poliética. Revista de Ética e Filosofia Política, São Paulo, v. 2, n. 1, 2014, p. 7 - 25 (disponível em http://revistas.pucsp.br/PoliEtica). Juris, 2015.

; CANTARINI, Paola. Teoria Poética do Direito, Rio de Janeiro: Lumen . O Conhecimento Imaginário do Direito, Curitiba: Prismas, 2017.

HEIL, Susanne. "Gefährliche Beziehung": Walter Benjamin und Carl Schmitt, Stuttgart: Metzler, 1996.

LUHMANN, Niklas. Das Recht der Gesellschaft, Frankfurt am Main: Suhrkamp, 1993. 
MBEMBE, Achille. Crítica da Razão Negra, trad. Sebastião Nascimento, São Paulo: $\mathrm{n}-1,2018 \mathrm{a}$.

Necropolítica, 3ạ . ed., trad. Renata Santini, São Paulo: n-1, 2018b.

SANTOS, Boaventura de Sousa. Para uma revolução democrática da justiça, São Paulo: Editora Cortez, 2007.

; MENESES, Maria Paula (orgs.). Epistemologias do Sul, São Paulo: Editora Cortez, 2010.

SCHMITT, Carl. "Legalität und Legitimität", in: Id. Verfassungsrechtliche Aufsätze. 3a. ed., Berlim: Duncker \& Humblot, 1985.

SERRANO, Pedro Estevam Alves Pinto. A Justiça na Sociedade do Espetáculo. Reflexões públicas sobre direito, política e cidadania, São Paulo: Alameda, 2015.

Autoritarismo e golpes na América Latina: Breve ensaio sobre jurisdição e exceção, São Paulo: Alameda, 2016.

SOUSA SANTOS, Boaventura de. Epistemologias do sul, São Paulo: Editora Cortez, 2010.

2007.

. Para uma revolução democrática da justiça, São Paulo: Editora Cortez,

SOUZA, Danigui Renigui Martins de. "Estado de exceção: Giorgio Agamben entre Walter Benjamin e Carl Schmitt" , in: Princípios: Revista de Filosofia, Natal: UFRN, v. 25 , n. $47, \quad 2018, \quad$ p. 35 - 58 (disponível em https://periodicos.ufrn.br/principios/article/view/12733).

THURSCHWELL, Adam. "Specters of Nietzsche: Potential Futures for the Concept of the Political in Agamben and Derrida". 2002. in: Academia.Edu (disponível em https://www.academia.edu/11538495/Specters of Nietzsche Potential Futures for the Concept of the Political in Agamben and Derrida).

VALIM, Rafael. Estado de Exceção: a forma jurídica do neoliberalismo, São Paulo: Contracorrente, 2017.

VILANOVA, Lourival. "Teoria Jurídica da Revolução. Anotações à margem de Kelsen", in: Revista Brasileira de Estudos Políticos, n. 52, Belo Horizonte: UFMG, 1981 (disponível https://edisciplinas.usp.br/pluginfile.php/340003/mod resource/content/1/Vilanova\%2 0 -

\%20Teoria\%20Jur\%C3\%ADdica\%20da\%20Revolu\%C3\%A7\%C3\%A30\%20rev\%20 bras\%20estudos\%20politicos\%20v.52.pdf). 
WILDE, Marc de. Verwantschap in Extremen. Politieke Theologie bij Walter Benjamin en Carl Schmitt, Amsterdam: Amsterdam University Press, 2008.

ŽlŽEK, Slavoj. Antígona, trad.: Francisco López Martín, Madri: Akal, 2017. 